REFLECTIVE PIECE

\title{
Navigating a Difficult Journey: Reflections on How a Student-Faculty Partnership Helped Address Racial Tensions in a Social Science Course
}

*Victoria Reyes, Assistant Professor, University of California, Riverside, USA

Kirsten Adams, Bryn Mawr College, Class of 2016, USA

Contact: vreyes@ucr.edu

\section{INTRODUCTION}

Racial injustice is a hallmark of the United States. In the classroom, many social science and humanities courses delve into moments of racial injustice in history and contemporary events. Classrooms, however, are not only places to discuss contemporary politics and inequality; they are also places where racial tensions can arise from misunderstandings, wellintended but misspoken comments, and disagreements in points of view. In this essay, we reflect on our faculty-student pedagogical partnership experience as it relates to navigating racial dynamics that arise in the classroom. Our insights into how to incorporate a facultystudent partnership approach in addressing tensions, obstacles, or sensitive topics that arise can provide lessons to others in how to navigate these dilemmas. Understanding how to address sensitive contemporary events that occur both outside and inside the classroom is particularly important as the United States now operates under a presidency that is rife with particularly harmful racial, gendered, and migration-related propaganda. We begin this essay by describing our faculty-student partnership. Next, we shift focus to how we addressed racial tensions that emerged in the classroom. Finally, we end with a reflection on how our experience influenced our understanding of our role in learning and teaching in the classroom.

\section{OUR PARTNERSHIP}

During the spring semester of the 2015-2016 academic year, Kirsten, a Bryn Mawr senior majoring in Anthropology, with a minor in Education, and Victoria, then a second-year Assistant Professor at Bryn Mawr, were paired for a pedagogical partnership through the Students as Learners and Teachers (SaLT) program at Bryn Mawr and Haverford Colleges. Through this program, Kirsten visited Victoria's class once a week and took detailed observation notes, and we met weekly to discuss classroom dynamics, review Kirsten's notes and feedback, 
and address Victoria's questions. In addition, Victoria participated in a seminar with other new faculty, and Kirsten participated in weekly meeting with other student partners, both facilitated by the director of the SaLT program. Victoria was compensated for her participation with a reduced teaching load and Kirsten with course credit.

From the beginning, we strove to create a partnership in which we were relative equals and to establish trust with one another given the inherent power dynamics between a faculty member and an undergraduate student. We explicitly recognized that we each had valuable knowledge and that we were in the partnership to learn from each other. Victoria stated her desire to get critical feedback on her teaching, and while Kirsten initially felt anxious about her new role as a consultant and partner-due to the misconceptions students and professors have about the role(s) they play in the college setting (e.g., many students are taught to not question authority figures, in this context, their professors)-she quickly realized the reasons she had anxieties were unfounded. Victoria played a crucial role in relieving Kirsten's initial worry. As the partnership grew and we got closer, Victoria's openness and honesty with Kirsten showed her how invested, committed, and comfortable Victoria was with her, and so Kirsten was better able to open up herself to the partnership as well. Through ongoing dialogue in person, over email, and on the phone, we were able to address difficult dynamics in the classroom, particularly those around racial tensions (see Reyes \& Adams, 2017, for a discussion of how they used their partnership to manage apathetic students in a different classroom).

\section{ADDRESSING RACIAL TENSIONS}

The class that was the context of Victoria's and Kirsten's partnership was a 200-level course on social science research methods in the Growth and Structure of Cities Department, which meets the quantitative requirement at Bryn Mawr and Haverford Colleges. The first half of the course covers basic quantitative techniques, and the second half focuses on other types of social scientific methods. Students played an active role in the course through leading portions of the discussion. In general, students in this class were engaged with one another and the content of the course.

The April 13th, 2016 session was a discussion-based session on content analysis. In the readings, we explored how scholars used content analysis in the course of their research on institutionalizing the concepts of race and ethnicity. The week before, we had a discussion on race and college admissions, and Victoria prefaced that class with a comment on respecting and listening to one another on what are sensitive and controversial topics. However, Victoria did not reiterate this position for the April 13th session. One of the discussion leaders presented a question to the class regarding what their experiences were in reading and working with high school history textbooks. In the course of the discussion, tension between students became palpable following comments about the role of race (or lack thereof) in the teaching of history. In short order, students then began interrupting one another. Victoria stopped the interruptions in order to let each student be able to contribute to the discussion, after which she made a comment regarding how race cannot be disentangled from U.S. history, and how different racial groups have been racialized in different ways. Victoria then shifted to the next point of the discussion. 
Leaving the class, Victoria thought she diffused the situation but wanted to doublecheck with Kirsten via the classroom notes she takes, which had spaces allotted for our questions to one another. The ongoing dialogue set by the pedagogical partnership allowed Victoria to not feel confused or unsure of how to respond to conflicts and tensions that arose in the classroom. In effect, this was because Kirsten had become an institutionalized support system for Victoria. Due to our continued conversations, Victoria was able to build trust with Kirsten as a student mirror that reflected back another perspective on classroom dynamics, and touching base with Kirsten became a routine after class, and something to which Victoria looked forward. As such, the pedagogical partnership cultivated, from Victoria's perspective, a view of classroom observers as helpful guides with different perspectives, with whom she could brainstorm ideas, rather than as judgmental figures in the classroom that provoked anxiety because of her classroom performance.

When Victoria touched base with Kirsten regarding the April $13^{\text {th }}$ class, Kirsten agreed that giving her own perspective and shifting the focus was appropriate and a good response to the situation. Seeing how open, honest, and vulnerable Victoria was with Kirsten in this situation, and throughout the partnership, helped Kirsten feel like she was truly Victoria's equal and partner. Reciprocally, Kirsten, being a student who had experienced a similar event, was able to offer Victoria a perspective of how students might have felt after the incident, as well as indicate what students needed in order to process the incident and get back on track.

Although her talk with Kirsten alleviated some of the fears she had regarding how she handled the aforementioned situation, Victoria's understanding of what happened was dramatically altered the next day when a student came to her office hours. This student told her that she felt silenced in class, branded as a racist, and that this was not the first time sheand another student-felt offended or that their experiences were invalidated. She then discussed how social media played a role in the aftermath of the class where at least one student posted a message about the class with a coded reference to her and other students, and that some other classmates "liked" the post. The student then told of other encounters after class that involved apologies, crying, and rejections. Victoria was blindsided by what the student reported, and she was greatly concerned with the dynamics of the class.

The already-set-in-place pedagogical partnership with Kirsten allowed Victoria to not get overwhelmed with the tensions the student reported that occurred both within and outside of the classroom following the event. Even at a place like Bryn Mawr College, which purposefully creates space to discuss pedagogy, in previous semesters of teaching there, Victoria had felt alone as she tried to navigate the teaching, research, and service responsibilities she had as a tenure-track faculty member. Both the weekly discussions with Kirsten and those that occurred in the pedagogy seminar allowed Victoria to connect with varied members of the BiCollege community (Bryn Mawr and Haverford), facilitated a sense of belonging and ease, as well as supported the creation of a "brave space" (see the Spring 2016 issue of Teaching and Learning Together in Higher Education) where everyone was engaged in learning.

Because of their pedagogical partnership and the trust they had established, Victoria reached out to Kirsten once again, this time via email to arrange a phone interview to talk about what the student had disclosed to Victoria during her office hours. On the phone, Kirsten and Victoria were able to go through what occurred during the previous class, discuss the office 
hour meeting with the student, and additionally, Kirsten was able to share with Victoria an interaction that took place after class that also played a role in the situation. Victoria asked Kirsten about how her professors had handled similar events, and Kirsten was able to share a social media policy her professors had put in place for her Anthropology classes to remind students what is said in the classroom should remain there since it is where the context and intention can be preserved and respected. During our phone conversation, we both felt it was critical to make sure our end goal was for students to feel validated and heard while reminding them, during the next class session, of the expectations of respect and class confidentiality Victoria had in place for her classroom. As mentioned previously, student consultants provide another lens for professors to view classroom interactions by allowing for a mixture of perceptions and interpretations. At the conclusion of their phone conversation, Victoria and Kirsten both agreed they should reach into their toolbox of resources and support provided by the SaLT program and get further advice about the situation. Victoria then spoke with the Director of the SaLT program.

In response to these consultations, Victoria emailed two students to meet with her separately (she offered an option of meeting as a group, but both students preferred meeting separately) before the next class period to check in with how they thought class and the aftermath following the incident went. In one student's reply, they thanked Victoria for what she said following their comment. This student saw Victoria's response as affirming their point of view and they expressed appreciation for allowing them to express their thoughts and not be marked as "the angry person of color." In her reply to Victoria's initial email about meeting, the other student thanked Victoria for checking in and replied that she felt upset, hurt, and misunderstood about the situation.

In her individual meetings with these two students, Victoria asked them about how they felt class went and about what happened afterwards, and solicited their feedback on her plan to address what happened at the beginning of next class. At the beginning of the next session, Victoria drew on her conversations with Kirsten and the director of SaLT and prefaced her comments with her appreciation for the discussions they have in class. She noted that each of the students come to the class with varied backgrounds, points of view, and experience in talking about these issues. Victoria told the students that it was her hope that the class try and grapple to understand what each other is saying than talking to just get a particular point across. Victoria suggested a formula to follow if one feels hurt or offended or wants clarification on what someone else said: "I feel when you said because " Following this formula, students could avoid being on the defensive, because when anyone feels defensive or attacked, learning cannot happen. Victoria encouraged the students to be selfreflexive and think about why people are saying what they are saying.

Per the helpful advice from Kirsten, Victoria told the students that they should strive to think about what fellow students say-particularly at places like Bryn Mawr and Haverford, where students are especially cognizant of these things - in the best light and/or with the best intention. However, there is also a saying that "the road to hell is paved with good intentions," and so best intentions do not necessarily matter when people are hurt by what is said. This is why Victoria encouraged the above formula, which specifies why we agree/disagree or are upset with people. By being specific regarding our disagreements, we open up room for 
learning and dialogue, particularly because some students have more or less experience with talking about sensitive issues like race and history. Victoria does not believe in policing students' behavior, particularly outside of class, and wanting to affirm that people should freely express a wide array of emotions they feel, she encouraged the class to be aware of the intended and unintended consequences that come with these things and to understand our privilege. Victoria also discussed how one way of thinking about privilege is not having to think about what we say or how we act, and we need to be reflective about what we say and why (particularly if it causes someone else to be hurt). In the end-of-semester feedback, one student commented that [Victoria] "was always aware of any identity tension that arose and was a great diffuser," and another said that "[t]he instructor is willing to have tough conversations and confront issues in the class head on. I really enjoyed that."

This example illustrates how, in recent years, classrooms and college campuses across the U.S. have become sites of engagement, protest, and activism for social justice and change. To be successful, conversations about charged issues such as social injustice need to be handled respectfully. Victoria and Kirsten were able to work together to find a fair way to address the needs of the two students and the needs of the class, while validating the need for the conversation and respecting different beliefs.

\section{HOW OUR PARTNERSHIP INFLUENCED OUR UNDERSTANDING OF OUR ROLE IN LEARNING AND TEACHING}

As we have described, our faculty-student pedagogical partnership served as a forum to address racial tensions in the classroom. In doing so, we were able to reposition students in the class, Kirsten, and Victoria as active agents in our learning. This only works, however, if all of people involved so desire. For student consultants, participating in pedagogical partnership does more than fulfill a class requirement or provide a paycheck. It provides real-world skills, such as reflexivity and active listening, which will serve them in their lives as students and in their lives as professionals when they leave Bryn Mawr and Haverford. Additionally, because of the way they are socialized in school settings, many students believe their professors are allknowing individuals who are there to one-sidedly pour their knowledge into students' malleable minds. Further still, some students even feel disenfranchised when it comes to their educations, feeling like they have no knowledge of their own to share with their professors. This partnership dispels those myths and shows both faculty and student participants, as well as the students in the faculty members' classes, that we should all be there to learn and grow from each other.

For faculty, participating in pedagogical partnership does more than afford a course release during the semester. It provides a valuable space and time to reflect on pedagogy, something that may fall to the wayside during the first few years on the tenure-track as faculty balance the required research, teaching, and service roles that are required. In particular, Victoria was able to take away two important pedagogical strategies from the seminar and partnership with Kirsten: flexibility and the role of students in the classroom. In terms of flexibility, she discovered how essential it is to foster a learning environment. This involves not over-planning classes, catering to the needs not only of the class as a whole but also to individual sessions, students, and subjects, tensions, and/or obstacles that arise. Similarly, 
Victoria also left the partnership seeing students as agents of their own learning. For example, being able to "punt" questions Victoria has about the course and its direction to students themselves, and questions they have to one another, allows a classroom dynamic where students take ownership of their education. It also creates an environment where faculty and students can engage in conversations not only about the content of the class but also classroom dynamics.

In addition to these benefits, partnership addresses the misconceptions some students and professors have about their roles in the classroom and the misconception that asking for help is a sign you are less knowledgeable than others. Throughout the duration of Victoria and Kirsten's partnership, both reached out to others when they were not sure of what to do or say, whether to each other or to students in the classroom. Bryn Mawr has a rigorous culture and is a place where many of its community members try to do everything on their own because they believe they can handle it all. Although there is no doubt that they are capable of handling myriad responsibilities and challenges, one thing both professors and students forget is that they do not have to do it alone. For both Victoria and Kirsten, their partnership gave each of them another person on campus to reach out to, confide in, and look to for advice. Together they were able to learn from and help each other be even more confident in their roles and abilities on campus and beyond (for similar reflections, see Reyes \& Adams, 2017).

\section{NOTE ON CONTRIBUTORS}

Victoria Reyes is an Assistant Professor in Sociology at University of California, Riverside.

Kirsten Adam is an undergraduate student studying Anthropology and Education at Bryn Mawr College.

\section{REFERENCES}

Reyes, V., \& Adams, K. (2017). Managing apathetic and disruptive students. Teaching and Learning Together in Higher Education, 22. Retrieved from http://repository.brynmawr.edu/tlthe/

Teaching and learning together in higher education. (2016) Retrieved from http://repository.brynmawr.edu/tlthe/ 